Thorax (1974), 29, 343.

\title{
Significance of prolonged peripheral vasoconstriction after open-heart surgery
}

\author{
H. R. MATTHEWS, J.B. MEADE, and C. C. EVANS
}

Cardio-thoracic Surgical Centre, Broadgreen Hospital, Thomas Drive, Liverpool L14 3LB

\begin{abstract}
Matthews, H. R., Meade, J. B., and Evans, C. C. (1974). Thorax, 29, 343-348. Significance of prolonged peripheral vasoconstriction after open-heart surgery. Abnormally prolonged peripheral vasoconstriction has been detected prospectively by means of a toe temperature nomogram in $15(11.5 \%)$ out of 131 patients following cardiopulmonary bypass. This state has been associated with a $53 \%$ incidence of hospital death, a detectable pathological cause in all cases, and in seven of the 15 cases it was the first or only evidence of a circulatory disorder. It is apparent that toe temperature monitoring after open-heart surgery gives early warning of a wide variety of potentially serious pathological processes, permitting effective treatment of the underlying cause before irreversible changes occur. It has become an indispensable part of routine postoperative care in our unit and is regarded as the simplest and most effective method of monitoring the circulation currently available.
\end{abstract}

Measurements of toe temperature after openheart surgery (OHS) have shown that patients without circulatory impairment have a remarkably constant peripheral warm-up pattern as vasoconstriction disappears and the normal vasodilated state is restored. The precise time and temperature limits for this recovery in our unit are defined by a nomogram (Matthews, Meade, and Evans, 1974) which it was hoped would facilitate the early detection and treatment of circulatory impairment following cardiac surgery.

This paper reports our prospective experience with the method since January 1973 when it was added to existing regimens for postoperative care.

\section{MATERIALS AND METHODS}

Toe temperatures were plotted against the nomogram on 131 consecutive patients after OHS from 1 January 1973. Sixty-eight were male and 63 female with ages ranging from 10 to 65 years. Operations performed were aortic valve replacement (39), mitral valve replacement (39), double valve procedures (20), correction of congenital heart defects (18), saphenous vein aortocoronary bypass graft (10), removal of left atrial myxoma (3), excision of left ventricular aneurysm (1), and pericardiectomy (1).

The methods used with regard to operative technique, postoperative care, and data collection were as previously described (Matthews et al., 1974). All temp- erature readings were taken to the nearest $0.5^{\circ}$ and are in degrees centigrade.

\section{RESULTS}

One hundred and sixteen patients reached a toe temperature of $34^{\circ}$ within the time limits defined by the nomogram. Fifteen patients exceeded these limits by intervals ranging from 1 to 48 hours (mean 7.5 hours), giving an incidence for prolonged vasoconstriction of $11.5 \%$. The principal features of each case are shown in the Table.

POSTOPERATIVE MORTALITY Eight (53\%) of the 15 patients with an abnormal warm-up pattern died without leaving hospital. Seven $(6 \%)$ of the 116 patients with a normal warm-up pattern died without leaving hospital. This difference is highly significant $\left(\mathrm{P}<0.001\right.$ ( $\chi^{2}$ analysis)). Hospital mortality for the 131 patients was $11.5 \%$.

Death in the eight patients with an abnormal pattern was due primarily to myocardial failure in three (days $4,10,21$ ), respiratory failure in four (days 9, 17, 21, 47), and cerebral embolism following removal of clot from the left atrium in one (day 2). Death in the patients with a normal pattern was due to respiratory failure in three (days 10,13,44), cerebral infarction in two (days $7,10)$, ventricular arrhythmia in one (day 21 ), and 
T A B L E

CLINICAL DETAILS OF PATIENTS SHOWING PROLONGED PERIPHERAL VASOCONSTRICTION AFTER OHS

\begin{tabular}{|c|c|c|c|c|c|c|c|c|c|}
\hline Case & Sex & Age & Op. & $\begin{array}{l}\text { Warm-up } \\
\text { time (hr) }\end{array}$ & IPPV & Cause & Circulation & $\begin{array}{l}\text { Treatment and } \\
\text { Response }\end{array}$ & Result \\
\hline I.W. & $\mathbf{F}$ & 49 & MVR & 16.00 & + & Concealed & Low BP and UO & Reoperation- & Alive and well \\
\hline E.H. & $\mathbf{M}$ & 51 & MVR & 17.50 & + & $\begin{array}{l}\text { Peripheral } \\
\text { vascular } \\
\text { disease }\end{array}$ & Normal & Nil-warmed & $\begin{array}{l}\text { Died day } 9 \\
\text { respiratory } \\
\text { failure }\end{array}$ \\
\hline A.G. & $\mathbf{M}$ & 60 & AVR & 15.00 & 一 & Hypovolaemia & Normal & Transfused- & Alive and well \\
\hline C.M. & $\mathbf{M}$ & 56 & MVR & 9.00 & - & $\begin{array}{l}\text { Myocardial } \\
\text { failure }\end{array}$ & Normal & Nil-warmed & $\begin{array}{l}\text { Died day } 4 \\
\text { myocardial }\end{array}$ \\
\hline N.D. & $\mathbf{F}$ & 56 & AVR/MVR & 7.50 & 一 & Myocardial & Normal & Nil-warmed & Alive and well \\
\hline R.R. & $\mathbf{F}$ & 46 & MVR & 9.50 & - & $\begin{array}{l}\text { Myocardial } \\
\text { failure }\end{array}$ & Low UO & $\begin{array}{l}\text { Inotropy- } \\
\text { warmed }\end{array}$ & $\begin{array}{l}\text { Died day } 21 \\
\text { myocardial }\end{array}$ \\
\hline A.H. & $\mathbf{F}$ & 52 & $\begin{array}{l}\text { AVR/mitral } \\
\text { valvotomy }\end{array}$ & 14.50 & - & $\begin{array}{l}\text { Concealed } \\
\text { haemorrhage }\end{array}$ & Low BP and UO & $\begin{array}{l}\text { Reoperation- } \\
\text { warmed }\end{array}$ & $\begin{array}{l}\text { Died day } 21 \\
\text { respiratory }\end{array}$ \\
\hline G.H. & $\mathbf{M}$ & 65 & AVR & 11.00 & 一 & $\begin{array}{l}\text { Concealed } \\
\text { haemorrhage }\end{array}$ & Normal & $\begin{array}{l}\text { Drained- } \\
\text { warmed }\end{array}$ & $\begin{array}{l}\text { Died day } 17 \\
\text { respiratory }\end{array}$ \\
\hline K.M. & $\mathbf{F}$ & 28 & AVR/MVR & 10.00 & + & $\begin{array}{l}\text { Myocardial } \\
\text { failure }\end{array}$ & Low BP and UO & $\begin{array}{l}\text { Inotropy- } \\
\text { warmed }\end{array}$ & $\begin{array}{l}\text { Died day } 47 \\
\text { respiratory }\end{array}$ \\
\hline E.S. & $\mathbf{F}$ & 56 & MVR & 12.50 & 一 & $\begin{array}{l}\text { Myocardial } \\
\text { failure }\end{array}$ & Low BP and UO & $\begin{array}{l}\text { Inotropy- } \\
\text { warmed }\end{array}$ & Died day 2 \\
\hline W.G. & $\mathbf{M}$ & 53 & AVR & 10.00 & - & Hypovolaemia & Normal & Transfused- & Alive and well \\
\hline $\begin{array}{l}\text { A.L. } \\
\text { D.C. }\end{array}$ & $\begin{array}{l}\mathbf{F} \\
\mathbf{F}\end{array}$ & $\begin{array}{l}57 \\
49\end{array}$ & $\begin{array}{l}\text { AVR/MVR } \\
\text { ASD }\end{array}$ & $\begin{array}{r}9.75 \\
11.75\end{array}$ & \pm & $\begin{array}{l}\text { Hypocarbia } \\
\text { Circulatory } \\
\text { overload }\end{array}$ & $\begin{array}{l}\text { Low BP and UO } \\
\text { Low UO }\end{array}$ & $\begin{array}{l}\text { Nil-warmed } \\
\text { Diuretic- } \\
\text { warmed }\end{array}$ & $\begin{array}{l}\text { Alive and well } \\
\text { Alive and well }\end{array}$ \\
\hline
\end{tabular}

$\overline{A V R}=$ aortic valve replacement; $M V R=$ mitral valve replacement; $A S D=$ atrial septal defect; $B P=$ blood pressure; $U O=$ urine output.

renal failure following a hypotensive episode at the start of operation in one (day 11).

CAUSE OF PROLONGED VASOCONSTRICTION A specific pathological cause for the prolonged vasoconstriction was identified in all 15 cases. This was myocardial failure in six, hypovolaemia in three (due to incorrectly placed central venous pressure cathether in two), concealed haemorrhage in three (without hypovolaemia as the venous pressure was maintained by transfusion), peripheral vascular disease in one, circulatory overload in one, and hypocarbia while on IPPV $\left(\mathrm{PCO}_{2}<30 \mathrm{mmHg}\right)$ in one.

CIRCULATORY STATUS At the time that the warmup curve first became abnormal seven patients exhibited no other evidence of a circulatory disorder. The remaining eight patients were all oliguric $(<30 \mathrm{ml} /$ hour $)$ and five were hypotensive $(<100 \mathrm{mmHg}$ systolic) .

THERAPY Four patients were given no treatment in spite of the prolonged vasoconstriction. One of these (E.H.) was known to have lower aortic obstruction with absent foot pulses before operation. The thumb temperature was therefore used to monitor his circulatory recovery. As the thumb warmed within the limits of the nomogram (although the toe did not) no treatment was con- 0 sidered necessary. The patient subsequently died 3 from chronic respiratory failure. The other three $\delta$ patients (two with myocardial failure and one with hypocarbia) had all begun to warm peripherally 을 and were merely observed. All subsequently warmed and two survived; the third (C.M.) is considered in greater detail below.

Eleven patients had specific treatment because $\mathscr{\sigma}$ of their abnormal vasoconstriction. The three with $N$ hypovolaemia all responded to transfusion by $\mathbb{\omega}^{N}$ warming peripherally and survived. Of the three patients with concealed haemorrhage two o required reoperation before warming peripherally but one of these subsequently died; the third $\stackrel{\infty}{\rightarrow}$ (G.H.) responded to treatment by intercostal $\square$ catheter alone and is described below. Four patients were treated with inotropic agents for $\stackrel{\mathbb{\Omega}}{\stackrel{D}{ }}$ myocardial failure-three responded and warmed $\stackrel{\mathbb{D}}{\Omega}$ peripherally but died in spite of this (from myo- 응 cardial failure, chronic respiratory failure, and 
cerebral embolism); the fourth was quite unresponsive to treatment and died of primary myocardial failure. The treatment of the remaining patient (D.C.) is described below.

\section{CASE REPORTS}

CASE 1 Figure 1 is the toe temperature record of G.H., in whom prolonged vasoconstriction led to the discovery of concealed haemorrhage. The patient, a man aged 65, was not on IPPV after aortic valve replacement. During operation the right pleura had been opened and drained. Six hours after operation his pulse, blood pressure, urine output, and general condition were entirely satisfactory, but he had failed to
CASE 2 Figure 2 is the record of D.C., in whom prolonged vasoconstriction was caused by circulatory overload. The patient, a woman aged 49, was not on IPPV after closure of a secundum atrial septal defect, with mild pulmonary hypertension. Four hours after operation the toe temperature had risen to $31^{\circ}$ but during the next hour it dropped to $29^{\circ}$. Blood pressure and urine output were satisfactory at that time. Half an hour later the normal limits of warm-up were exceeded. In view of her age and diagnosis it was thought that she might require a higher filling pressure to restore a normal circulation, and the venous pressure was raised from 7 to $15 \mathrm{cmH}_{2} \mathrm{O}$ by transfusion. This failed to produce any improvement. Blood gases and serum electrolytes were normal. In an empirical

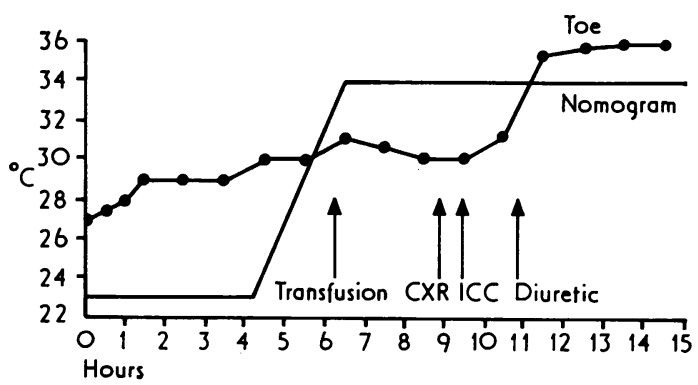

FIG. 1. Abnormal warm-up pattern due to concealed haemorrhage in patient G.H. after aortic valve replacement, plotted against the appropriate nomogram. $C X R$-chest radiograph; ICC-intercostal catheter.

$\begin{array}{lrrrrrrrrrrrrrrrl}\text { Systolic blood pressure } & 120 & 110 & 120 & 120 & 125 & 115 & 110 & 120 & 130 & 130 & 130 & 120 & 130 & 120 & 120 \mathrm{mmHg} \\ \text { Pulse rate } & 100 & 100 & 100 & 100 & 100 & 88 & 88 & 84 & 84 & 88 & 90 & 80 & 84 & 88 & 90 / \mathrm{min} \\ \text { Central venous pressure } & 9 & 6 & 3 & 4 & 7 & 3 & 6 & 10 & 9 & 9 & 8 & 9 & 9 & 6 & 7 & \mathbf{c m H} \\ \text { Urine output } & 30 & 40 & 40 & 70 & 60 & 35 & 35 & 35 & 40 & 35 & 30 & 100 & 180 & 100 & 80 & \mathrm{ml} / \mathrm{hr}\end{array}$

warm peripherally within the predicted normal limits. As the central venous pressure at this time was only $6 \mathrm{cmH}_{2} \mathrm{O}$ it was thought that he might be hypovolaemic and the venous pressure was raised to $10 \mathrm{cmH}_{2} \mathrm{O}$ by transfusion. This failed to produce any improvement in the peripheral circulation, suggesting that the initial diagnosis had been incorrect. Blood gases and serum electrolytes were normal, but a second postoperative chest radiograph showed a considerable fluid collection in the right pleura despite the presence of a drainage tube. Chest aspiration revealed liquid blood and a further intercostal tube was inserted; $1500 \mathrm{ml}$ of blood were drained and the patient then warmed tc $34^{\circ}$ within 1.5 hours. He was discharged from the intensive care unit on the second postoperative day but was readmitted on the seventh day with a virulent Escherichia coli pneumonia from which he died on the seventeenth day. attempt to improve the peripheral circulation chlorpromazine $(12.5 \mathrm{mg}$ iv) was given but without effect. Myocardial failure was then considered as a possible cause for the persistent vasoconstriction but there was no response to intravenous calcium chloride or isoprenaline. It was then argued that circulatory overload might be responsible for ventricular overdistension, and frusemide (40 $\mathrm{mg}$ iv) was given 10.5 hours after operation. Within 1.5 hours $1200 \mathrm{ml}$ of urine was passed and the temperature rose to $34.5^{\circ}$. The patient subsequently remained warm and made an uncomplicated recovery.

CASE 3 Figure 3 is the record of C.M., in whom a lesser degree of abnormality than those described above was associated with early death from myocardial failure. The patient, a man aged 56, was not on IPPV after mitral valve replacement; five hours 


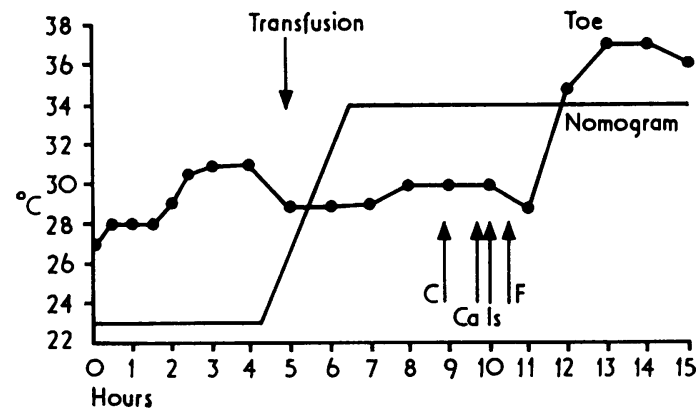

FIG. 2. Abnormal warm-up pattern due to circulatory overload in patient D.C. after closure of atrial defect. $C$-chlorpromazine; $\mathrm{Ca}$-calcium chloride; Isisoprenaline; $F$-frusemide.

Systolic blood pressure Pulse rate

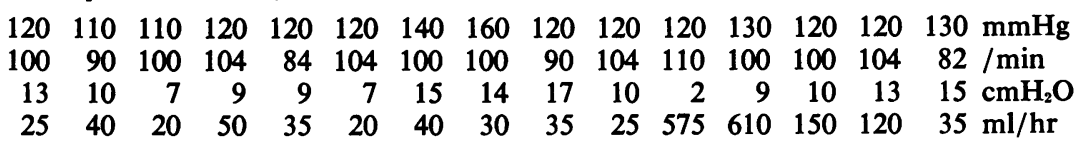

Urine output

after operation his toe temperature curve exceeded the predicted normal limits but the warm-up appeared to have begun and no specific therapy was given. In the following hour $15 \mathrm{ml}$ of urine were passed and the toe warmed to $29 \cdot 5^{\circ}$. Frusemide ( $20 \mathrm{mg}$ iv) was given with some response. By nine hours after operation he had warmed spontaneously to $34^{\circ}$ but this level was maintained for only four hours. Peripheral cooling below the limit of the nomogram $\left(34^{\circ}\right)$ then occurred, accompanied by severe oliguria which did not respond to diuretics. Treatment for presumed myocardial failure was begun with calcium chloride, glucose and insulin, and an isoprenaline infusion. A good diuresis followed, but despite the maintenance of an adequate blood pressure the toe temperature continued to drop, $\overline{0}$ indicating that the underlying problem had not beeno successfully corrected. An inexorable decline con- $\stackrel{\odot}{\varrho}$ tinued in spite of increasing the dose of isoprenaline $\overrightarrow{\vec{A}}$ and adding digitalis and, later, intermittent positive $\frac{O}{3}$ pressure ventilation. Thirty-nine hours after operation the toe temperature was only $26^{\circ}$. On the fourth postoperative day the patient died with a florid 'low-output' syndrome. Necropsy confirmed that death was due to myocardial failure but gave no indication
Systolic blood pressure Pulse rate Central venous pressure Urine output

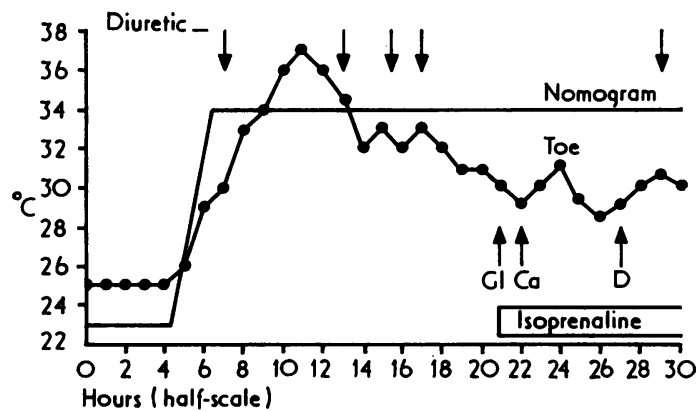

FIG. 3. Abnormal warm-up pattern and late cooling due to myocardial failure in patient C.M. after mitral valve replacement. $\mathrm{GI}-$ glucose and insulin; $\mathrm{Ca}-$ calcium chloride; $D$-digitalis.

$\begin{array}{rrrrrrrrrrrrrrr}105 & 130 & 120 & 120 & 120 & 115 & 115 & 120 & 110 & 100 & 95 & 110 & 105 & 110 & 115 \mathrm{mmHg} \\ 120 & 116 & 100 & 100 & 100 & 124 & 140 & 112 & 120 & 108 & 100 & 116 & 112 & 112 & 110 \quad / \mathrm{min} \\ 17 & 8 & 12 & 8 & 13 & 8 & 12 & 15 & 12 & 14 & 13 & 14 & 16 & 15 & 16 \\ 160 & 140 & 40 & 110 & 60 & 65 & 30 & 10 & 5 & 25 & 190 & 220 & 95 & 110 & 190 \mathrm{ml} / \mathrm{hr} \times 2\end{array}$


of the cause. The prosthesis was satisfactorily positioned and there was no evidence of disease in the other valves or the coronary arteries. This patient was operated on early in the series and treatment was unnecessarily delayed. It should have been begun much earlier but whether this would have prevented a fatal outcome is, of course, unknown.

\section{DISCUSSION}

Using the nomogram it has been a simple matter to identify patients showing abnormally prolonged peripheral vasoconstriction after OHS. Fifteen such cases are reported here. On the basis of this experience with the method we feel that certain clinically important conclusions are justified.

(1) Prolonged vasoconstriction has great prognostic significance. Exceeding the normal limits of warm-up was associated with a ninefold increase in hospital mortality (from $6 \%$ up to $53 \%$ ). The fact that death occurred after an interval of weeks in some cases does not necessarily exclude a connection. Long-term renal, respiratory, and hepatic failure may all have their origin in an immediate postoperative period of diminished perfusion.

(2) Prolonged vasoconstriction has pathological causes. Ross, Brock, and Aynsley-Green (1969) showed that it could be caused by hypovolaemia. This was confirmed in some of these cases, but it is clear that many other causes can produce the same result, including an important group of patients with myocardial failure.

(3) Prolonged vasoconstriction is frequently the first or only evidence of a circulatory disorder. This has been demonstrated in cases 1 and 2 and was seen in seven of the 15 abnormal patients. This finding is not unexpected. In low cardiac output states (whether hypovolaemic or cardiogenic) the skin is a relatively non-vital organ and the cutaneous circulation will be bypassed in order to maintain the circulating blood volume to more essential organs such as the kidney and brain. In some instances this will be sufficient to maintain a normal blood pressure and urine output (that is, 'compensated shock') when only a low toe temperature will give evidence of the operation of a compensatory mechanism. The urine output is conventionally regarded as the most reliable simple index of cardiac output, but after OHS its value is considerably diminished by the fact that many patients have some degree of primary renal impairment and may be oliguric even with a normal circulation. If the toe temperature is normal then oliguria can confidently be diagnosed as renal in origin. If the toe temperature is abnormal then oliguria is likely to be due to pre-renal causes (case 3).

(4) Toe temperature can be relied upon to detect pathological states that are adversely affecting the circulation and will be unchanged by disorders that are not significantly affecting the circulation. It follows that abnormalities of toe temperature are in no way specific. They do not indicate what is wrong but that something is wrong. This applies not only to the immediate postoperative period but for as long as the patient is confined to bed. The nomogram requires that patients with a normal circulation should warm peripherally within certain limits but should also subsequently remain warm. Failure to do this is also pathological as demonstrated in case 3 .

(5) Abnormal vasoconstriction (whether in the form of an initial failure to warm or subsequent cooling) requires prompt diagnosis and appropriate treatment. The diagnosis in any individual situation will be based on evidence from conventional sources, including nursing and medical observations, laboratory analysis and radiography, and sometimes only on the basis of a favourable response to a therapeutic trial. Treatment must be directed to correcting the underlying cause. If this can be successfully achieved then peripheral vasodilatation will spontaneously follow and vasodilator drugs are not required. If the underlying cause proves totally resistant to treatment then the prognosis is extremely poor; only in these circumstances do vasodilator drugs have a placein the last hope that they may reduce the afterload on the failing heart. While we subscribe fully to the view that flow is generally more important than pressure in sustaining organ viability, the 'blanket' use of vasodilators is akin to treating the pain of peritonitis with morphine. Treatment must be begun early while the situation may still be reversible. Awaiting the development of hypotension, acidaemia and secondary organ damage will only increase the likelihood of death.

(6) Toe temperature provides a very sensitive index of the effectiveness or otherwise of specific therapeutic measures. This has been illustrated in the three case reports. This simplifies many clinical decisions. Many examples could be given. If a patient changes from sinus rhythm to rapid atrial fibrillation but does not cool peripherally then his circulation is not being adversely affected and he can be digitalized orally; if peripheral cooling does occur then intravenous therapy (despite the increased risk) is required. Similarly, if he is 
being weaned from IPPV and the blood gases are not entirely satisfactory the situation can be tolerated provided peripheral cooling does not occur-if it does then IPPV must be reinstituted. The toe temperature is also invaluable in indicating when a patient has been adequately transfused. The normal central venous pressure after any operation is simply that which will keep the toes warmer than $34^{\circ}$. Provided this level is maintained there is no benefit and considerable risk in transfusing the patient to a higher venous pressure.

(7) Toe temperature monitoring is in no sense in competition with existing methods of monitoring the circulation. It provides different information. Techniques are now available for continuous measurement of cardiac output by electromagnetic recordings of aortic blood flow (Williams et al., 1972). Although expensive and invasive, they measure the cardiac output in litres per minute but cannot determine if that output (particularly if low) is sufficient for the individual patient at a specific moment in his recovery. The toe temperature conversely will not quantitate the cardiac output but will indicate whether it is adequate or not for the metabolic needs at the time.

Because of these considerations toe temperature measurement has become an indispensable part of routine postoperative care in this unit. It gives early warning of a wide variety of potentially serious pathological processes and indicates accurately whether treatment has been successful.
It is simple, cheap, and non-invasive and can be used until the patient is ambulant. It carries no hazards, does not disturb sleep, and can be used for weeks at a time and reapplied at any time with a minimum of effort. We regard it as the simplest and most valuable method of monitoring the circulation currently available. We do not believe that minor reductions in temperature over a period of hours can be detected by hand and yet such changes may indicate the death of the patient days or weeks later. If there is a need to quantitate body core temperature after OHS then there is an even greater need to quantitate peripheral temperature.

\section{REFERENCES}

Matthews, H. R., Meade, J. B., and Evans, C. C. (1974). Peripheral vasoconstriction after openheart surgery. Thorax, 29, 338.

Ross, B. A., Brock, and Aynsley-Green, A. (1969). Observations on central and peripheral temperatures in the understanding and management of shock. British Journal of Surgery, 56, 877.

Williams, B. T., Sancho-Fornos, S., Clarke, D. B., Abrams, L. D., Schenk, W. G., and Barefoot, C.A. (1972). The Williams-Barefoot extractable blood flow probe. Journal of Thoracic and Cardiovascular Surgery, 63, 917.

Requests for reprints to: H. R. Matthews, F.R.C.S., Cardio-Thoracic Surgical Centre, Broadgreen Hospital, Thomas Drive, Liverpool L14 3LB. 